\title{
Preparation of PAN Spinning Solution with Fine Dispersion of Cellulose Microparticles
}

\author{
Jee-Woo Yang, Jong Sung Won, Da Young Jin, Ji Eun Lee, Won Ho Park, and Seung Goo Lee
}

Department of Advanced Organic Materials and Textile System Engineering, Chungnam National University, Daejeon, Republic of Korea

Correspondence should be addressed to Won Ho Park; parkwh@cnu.ac.kr and Seung Goo Lee; lsgoo@cnu.ac.kr

Received 12 November 2014; Accepted 25 March 2015

Academic Editor: Jin Zhu

Copyright (c) 2015 Jee-Woo Yang et al. This is an open access article distributed under the Creative Commons Attribution License, which permits unrestricted use, distribution, and reproduction in any medium, provided the original work is properly cited.

This study suggested the optimum conditions for the stable dispersion of cellulose microparticles in PAN spinning dope, which was prepared for spinning the fiber. Many research studies have investigated methods for preparing a variety of carbon fiber precursors in an attempt to control their characteristics according to the applications. In order to prepare PAN fiber that contains fine cellulose particles, it is important to create a uniformly dispersed spinning dope. Minimization of the cellulose particle size was subjected to heat treatment at various temperatures in order to reduce the cohesive force from the hydrogen bonds between the cellulose molecules. Carbonized cellulose microparticles were obtained for efficient dispersion using the physical method and the sedimentation method. Several instrumental analyses were conducted to study the characteristics of the particles and solutions with SEM, FT-IR, XRD, and a particle size analyzer. From the results, the dispersion of the PAN spinning dope with a chemical treatment was superior to the milling method followed by heat treatment. In this study, heat-treating cellulose microparticles at $400^{\circ} \mathrm{C}$ was found to be the most effective method.

\section{Introduction}

A carbon fiber is a type of fiber that contains over $90 \%$ carbon and it can be prepared by heat treatment of an organic fiber as a precursor. Carbon fiber applications are extended to the aerospace, defense, energy, ship-building, vehicle-manufacturing, sports, and leisure fields because of the material's excellent properties, including specific strength, specific modulus, and thermal stability. Recently, emerging energy saving and global warming issues have led to the acceleration of the application of lightweight materials, such as carbon fiber. Use of this fiber is especially promising in the aircraft industry because it is lightweight, has less volume change, and is stable under high temperatures and chemical attacks while retaining high strength and high modulus.

Carbon fiber is categorized into three groups based on the starting material: rayon-based carbon fiber, pitch-based carbon fiber, and PAN-based carbon fiber [1-4]. Rayon-based carbon fiber has good thermal properties and high modulus. The processing costs for pitch-based carbon fiber are affordable, which makes its use advantageous to manufacturers.
PAN-based carbon fiber is used in many kinds of composites, due to its high strength. Process development studies have been widely conducted because high performance carbon fiber can be obtained via stabilization and the carbonization process [5-7]. After the carbonization process of the wellcontrolled stabilization of PAN-based carbon fiber, that material's tensile and shear strength would be improved so that it can be applied to the composite material.

Due to the need for materials having excellent mechanical and thermal properties, various researches have been consistently developed into hybrid technology of carbon fiber materials. For example, carbon fiber, which has relatively high thermal conductivity and low thermal insulation, had limitations for use in rocket engine nozzle and nuclear reactor applications. These applications require materials that simultaneously feature high strength, lightweight, and insulation properties. To address these points, there is a need to develop a new type of carbon fiber. Recently, a high performance carbon fiber composite with inorganic nanofibers and cellulose nanoparticles has been reported [8]. Based on the results of thermal conductivities of carbon fiber 
with various precursors, the thermal conductivity of rayonbased carbon fiber, heat-treated at $1500 \mathrm{~K}$, was $20.5 \%$ lower than that of PAN-based carbon fiber heat-treated at $1600 \mathrm{~K}$. The thermal conductivity of rayon-based carbon fiber, heattreated at $2500 \mathrm{~K}$, was also found to be $16.7 \%$ lower than that of pitch-based carbon fiber, heat-treated at $2700 \mathrm{~K}$ [9]. Using this result, a study on lowering the thermal conductivity using a composite of PAN-based carbon fiber and microcellulose particles has been conducted [10].

In this study, the preparation, including dispersion of the cellulose particles, was investigated for PAN-based carbon composite fiber with cellulose particles in order to reduce the thermal conductivity of the composite fiber without decreasing its elasticity. The most important process for manufacturing a composite fiber is the dispersion of fine cellulose particles in the PAN dough. In this current study, the chemical method and the physical method were applied to enhance the dispersion. In the physical method, the size of the cellulose particles is reduced by heat treatment and mechanical milling. Finally, a PAN-based composite carbon fiber with cellulose particles can be produced. This result reveals the possibility of composite fiber preparation that will yield tailor-made properties. Further researches related to the analysis of the thermal properties and mechanical properties of composite carbon fiber are needed, and these will be conducted through ongoing research studies.

\section{Experimental Methods}

2.1. Materials. The polyacrylonitrile (PAN) precursor used as raw material for the carbon fiber was provided by Bluestar Fibres Co., Ltd., China, as $12 \mathrm{~K}$ fits, Single Tow uncrimped carbon fiber. Commercial-grade dimethylsulphoxide (DMSO) with a purity of $99 \%$ was used as the solvent for making the PAN dope. It was obtained from Samcheon Co., Ltd., a local supplier. Cellulose microcrystalline particles with an average Mw. of $\sim 80,000$ and bulk density of $0.6 \mathrm{~g} / \mathrm{mL}$ at $25^{\circ} \mathrm{C}$ were purchased from Sigma Aldrich Co., Ltd., USA.

2.2. Preparation of Cellulose Particles for Dispersion. Due to the large aspect ratio of the cellulose particles and the hydrogen bond between the molecules, it was difficult to disperse them in the PAN dope. To improve this dispersion and to increase its stability, the chemical treatment method and the physical treatment method were applied.

2.2.1. Chemical Treatment. Chemical treatment was performed using the following steps. Cellulose microcrystalline particles were added by $10 \mathrm{wt} \%$ into the DMSO solution containing $0.5 \mathrm{wt} \% \mathrm{LiCl}$. After stirring and swelling for $12 \mathrm{~h}$ at $70^{\circ} \mathrm{C}$, bonding could be eliminated by sonication. The samples were washed with deionized water several times and then dried for $12 \mathrm{~h}$ at $100^{\circ} \mathrm{C}$ in the vacuum dry oven.

2.2.2. Physical Treatment. The cellulose particles for dispersion were prepared by mechanical milling after heat treatment. The heat treatment conditions were $300^{\circ} \mathrm{C}, 350^{\circ} \mathrm{C}$, $400^{\circ} \mathrm{C}$, and $1,200^{\circ} \mathrm{C}$. Detailed heat treatment conditions are
TABLE 1: Heat treatment conditions of the cellulose particles.

\begin{tabular}{|c|c|c|c|c|}
\hline Sample & Condition & Heating rate & Soaking & Atmosphere \\
\hline Cel 00 & $\begin{array}{l}\text { Chemical } \\
\text { treatment }\end{array}$ & & & \\
\hline Cel 30 & $300^{\circ} \mathrm{C}$ & $300^{\circ} \mathrm{C} / 3 \mathrm{hr}$ & $4 \mathrm{hr}$ & Air \\
\hline Cel 35 & $350^{\circ} \mathrm{C}$ & $\begin{array}{c}350^{\circ} \mathrm{C} / 3 \mathrm{hr} \\
30 \mathrm{~min}\end{array}$ & $4 \mathrm{hr}$ & Air \\
\hline Cel 40 & $400^{\circ} \mathrm{C}$ & $400^{\circ} \mathrm{C} / 4 \mathrm{hr}$ & $4 \mathrm{hr}$ & Air \\
\hline Cel 40/120 & $1,200^{\circ} \mathrm{C}$ & $\begin{array}{c}400^{\circ} \mathrm{C} / 4 \mathrm{hr} \rightarrow \\
1,200^{\circ} \mathrm{C} / 4 \mathrm{hr}\end{array}$ & $4 \mathrm{hr}, 2 \mathrm{hr}$ & Air, $\mathrm{N}_{2}$ \\
\hline
\end{tabular}

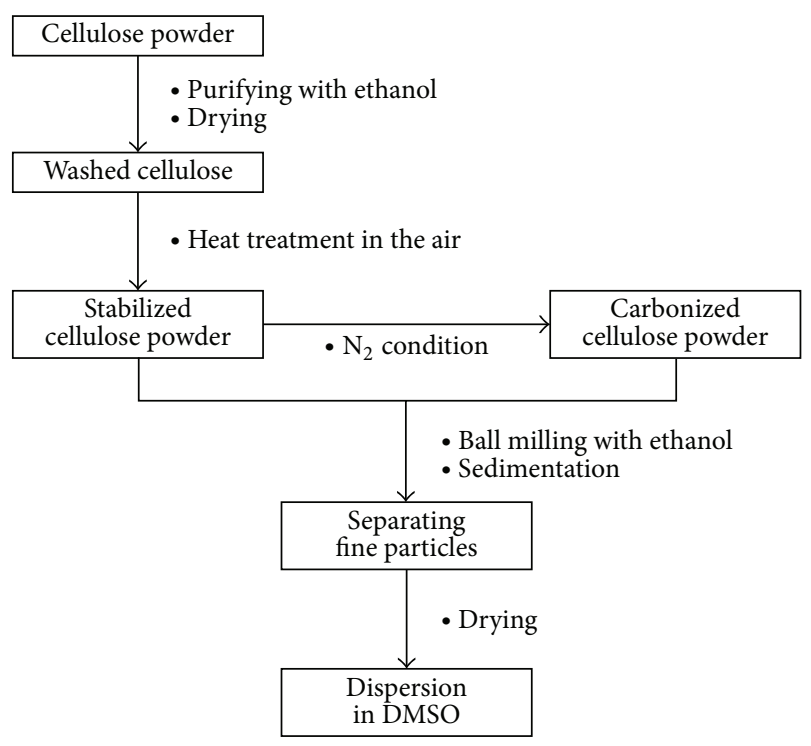

FIgURE 1: Preparation of the cellulose dispersed PAN dope.

shown in Table 1 . In the case of heat treatment at $1,200^{\circ} \mathrm{C}$, the cellulose particles heat-treated at $400^{\circ} \mathrm{C}$ were used for the 2 nd heat treatment at $1,200^{\circ} \mathrm{C}$ in $\mathrm{N}_{2}$. The manufacturing process for the PAN dope that contained cellulose particles consisted of three steps. In the first step, the cellulose particles underwent heat treatment. In the second step, the particles were dispersed. In the final step the stable DMSO solution was made. The detailed process used to prepare the PAN dope containing the dispersed cellulose particles is shown in Figure 1.

The heat-treated cellulose particles were ball milled with zirconia balls ( $3 \mathrm{~mm}$ in diameter) in a jar with ethanol for $48 \mathrm{~h}$. Before and after the milling, the size of the heat-treated particles was checked. The shape of the particles in the carbon fiber was determined by examining the fibers that were flattened by high pressure (more than 10-ton load) using an optical microscope (Optiphot 150, Nikon, Japan).

2.3. Preparation of the PAN-Carbon Fiber Having Cellulose Microparticles. In order to prepare a PAN dope containing heat-treated cellulose particles for spinning, the dispersion of cellulose particles should be stabilized in the dope by size reduction, a process that includes milling the particles and selecting microparticles by collecting $30 \%$ of the cellulose 
TABLE 2: PAN-DMSO dope containing heat-treated cellulose particles.

\begin{tabular}{|c|c|c|c|c|}
\hline Sample & PAN (wt $\%)$ & DMSO (wt\%) & Cellulose condition & Additional contents (wt\%) \\
\hline Cel 30 (1.0) & 17.82 & 82 & Heat-treated at $300^{\circ} \mathrm{C}$ & $0.18(1.0 \mathrm{wt} \%$ based on PAN $)$ \\
\hline Cel 35 (1.0) & 17.82 & 82 & Heat-treated at $350^{\circ} \mathrm{C}$ & 0.18 (1.0 wt $\%$ based on PAN) \\
\hline Cel $40(1.0)$ & 17.82 & 82 & Heat-treated at $400^{\circ} \mathrm{C}$ & 0.18 (1.0 wt $\%$ based on PAN) \\
\hline Cel 40 (1.5) & 17.73 & 82 & Heat-treated at $400^{\circ} \mathrm{C}$ & 0.27 (1.5 wt $\%$ based on PAN) \\
\hline Cel 40 (2.0) & 17.64 & 82 & Heat-treated at $400^{\circ} \mathrm{C}$ & 0.36 ( $2.0 \mathrm{wt} \%$ based on PAN) \\
\hline Cel 40/120 (1.0) & 17.82 & 82 & Heat-treated at $1,200^{\circ} \mathrm{C}$ & 0.18 (1.0 wt $\%$ based on PAN) \\
\hline Cel 40/120 (1.5) & 17.73 & 82 & Heat-treated at $1,200^{\circ} \mathrm{C}$ & 0.27 (1.5 wt $\%$ based on PAN) \\
\hline Cel 40/120 (2.0) & 17.64 & 82 & Heat-treated at $1,200^{\circ} \mathrm{C}$ & $0.36(2.0 \mathrm{wt} \%$ based on PAN $)$ \\
\hline
\end{tabular}

particles from supernatant fluid of the settled dope. Average particle size was measured using the particle size analyzer.

The spinning dope was prepared using various process parameters, such as cellulose heat treatment conditions and the amount of cellulose in the composite fiber. Detailed conditions for the dope are shown in Table 2. Slurry, which includes ground cellulose particles, was dried in the dry oven for $24 \mathrm{~h}$ at $90^{\circ} \mathrm{C}$. These dried particles were dispersed in the DMSO with a homogenizer for $2 \mathrm{~h}$. To classify the small particles, floating particles in the mass cylinder were selected in the equivalent sedimentation condition for the samples. The net weight of the cellulose that was used could be calculated from the remaining cellulose particles, which were found at the bottom of the cylinder. The final spinning dope, mixed with carbonized cellulose, DMSO, and PAN, was prepared as shown in Figure 2.

\subsection{Characterizations}

2.4.1. Thermal Analysis. The starting and ending point of the thermal decomposition of the cellulose due to heat treatment conditions were confirmed by the TG/DTA results (TA, TGA/SDTA 851e, Mettler-Toledo) with $\mathrm{N}_{2}$ atmosphere.

2.4.2. Morphology Observation. The microstructure of the cellulose particles was observed by a scanning electron microscope (SEM) (FE-SEM, XL30, Philips). The size and morphology changes could be compared with the treatment conditions.

2.4.3. Chemical Structure Analysis. The chemical structure of the heat-treated cellulose particles was examined by Fourier transformation infrared spectroscopy (FT-IR) (Magna IR550, Scinco). The spectra could be obtained from proper molecular vibrations in the range of $500 \mathrm{~cm}^{-1}-4000 \mathrm{~cm}^{-1}$.

2.4.4. Crystal Structure Analysis. The crystal structures of the carbonized cellulose were observed using an X-ray diffractometer (XRD) (D8 Discovery, Bruker) with the variations of the heat treatment temperature. The measurement was conducted in the range of $2 \theta=10^{\circ} \mathrm{C}-60^{\circ} \mathrm{C}$.

2.4.5. Particle Size Analysis. The particle size of the carbonized cellulose was obtained by particle size analyzer (LS 13 320, Beckman Coulter, Inc., USA).

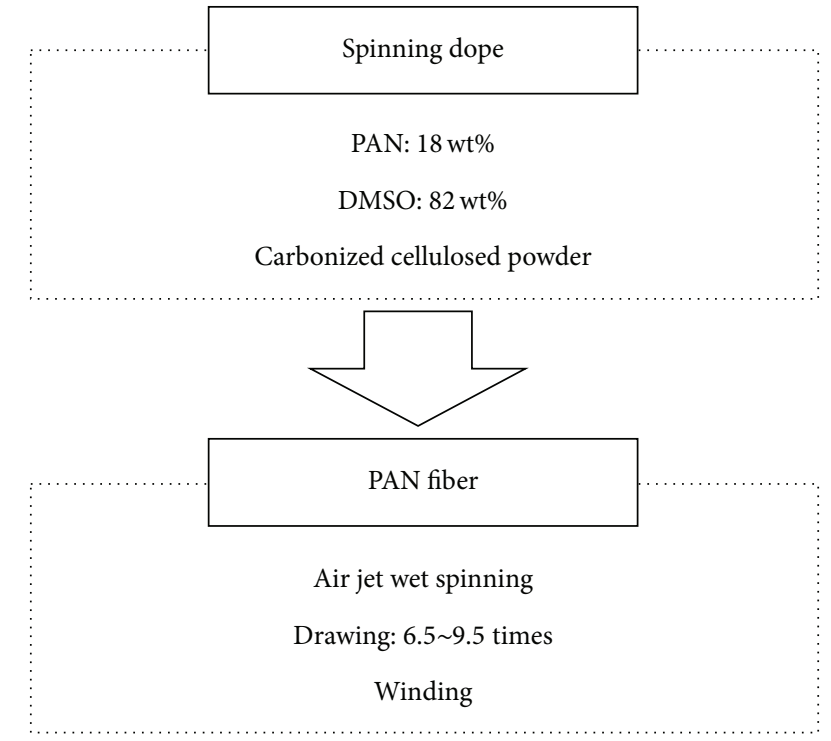

FIgure 2: Preparation process of the PAN fiber containing carbonized cellulose particles.

\section{Results and Discussion}

3.1. Cellulose Particles. Heat treatment was conducted in order to comprehend the thermal properties of the cellulose and to investigate the optimum treatment condition for the cellulose particles. The first step of this study involved preparing the dope with proper cellulose particles to spin the PAN fiber with stable dispersion. Because the stabilization and carbonization process is essential for preparing PANbased carbon fiber [11, 12], the heat-treating temperatures were chosen from the range of the stabilization temperatures for carbon fiber. The range for the optimum heat treatment condition was established based on the following thermal analysis results.

The results of the thermal decomposition of the cellulose examined by TG/DTA are shown in Figure 3. The weight loss of $5-6 \%$ until $100^{\circ} \mathrm{C}$, which was shown in region "a," was attributed to the evaporation of the physisorbed water. The main weight loss of the cellulose occurred in temperature range "b," about $260-350^{\circ} \mathrm{C}$, due to the breakdown of the anhydrous glucose bond by the pyrolysis. It arose from the evaporation of water vapor, tar, $\mathrm{OH}, \mathrm{CO}$, and $\mathrm{CO}_{2}$ in 


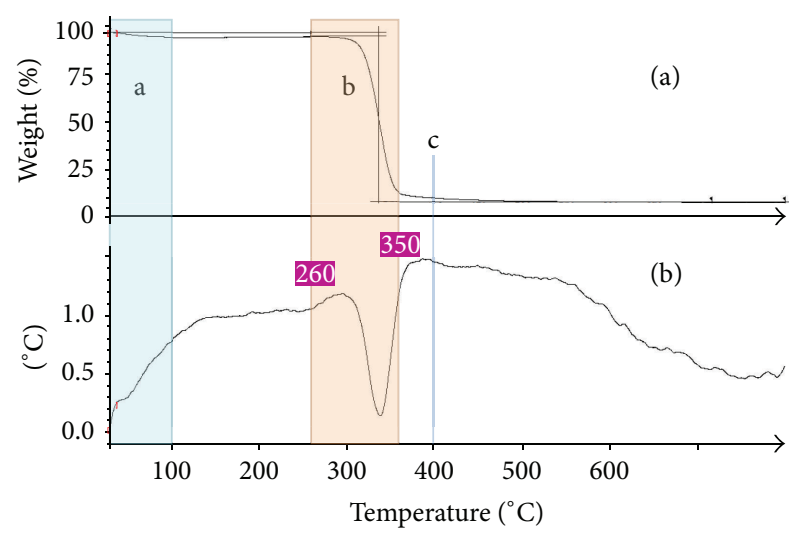

Figure 3: TG and DTA curves of the cellulose particles.

the decomposition process of levoglucosan from the debonding of the glycosidic unit. The weight loss occurred continuously, via the breakdown of anhydrous cellulose, with elevating temperature until the temperature reached $400^{\circ} \mathrm{C}$. This result was similar to the results reported by Brunner [13] and Fengel and Wegener [14]. By way of explanation, the thermal decomposition of cellulose occurred because the side groups $(\mathrm{H}, \mathrm{OH})$ were removed and were disintegrated as small molecules of the carbonyl compound by chain scission from the ring opening reaction as the temperature increased [15]. The maximum rate of decomposition was found at $335^{\circ} \mathrm{C}$, via the DTA results. After that temperature, the decomposition rate was decreased linearly. In this experiment, the final weight loss was $87 \%$. Even though the weight decreased continuously as the temperature reached $400^{\circ} \mathrm{C}$, the rate of loss was lower. These phenomena could be explained by the thermal decomposition of additives as the result of FT-IR experiments. The final product of cellulose through heat treatment was amorphous carbon.

\subsection{Morphology of Cellulose}

3.2.1. Particle Size and Distribution. In order to spin the PAN dope containing the cellulose particles, the size of the cellulose particle should be reduced by ball milling in order to enable the particles to pass through the spinning nozzle ( $50 \mu \mathrm{m}$ in diameter). Moreover, the cellulose particle size should be smaller than the final fiber diameter of the PAN, in the range of $4-15 \mu \mathrm{m}$. The particle size and size distribution were decided by the results of the particle size analysis, as shown in Figure 4. The measured data are shown in Table 3 where the average particle size and the distribution of the Cel 40 particle sample were $4.71 \mu \mathrm{m}$ and $3.88 \mu \mathrm{m}$, respectively, showing the smallest value in this study. As shown in Figure 3, the cellulose particles were initially decomposed in the range of $260^{\circ} \mathrm{C}-350^{\circ} \mathrm{C}$. When the temperature exceeded $400^{\circ} \mathrm{C}$, the thermal decomposition was terminated and most of the hydrogen bonded organic substance was removed. Finally, the cellulose particles were converted to amorphous carbon with a weak bond, making it easier for the particles to be ground due to the highest milling efficiency at a condition of Cel 40.
TABLE 3: Particle size analysis of the cellulose particles after heat treatment and milling.

\begin{tabular}{lccc}
\hline Sample & $\begin{array}{c}\text { Mean size } \\
(\mu \mathrm{m})\end{array}$ & $\begin{array}{c}\text { Standard } \\
\text { deviation } \\
(\mu \mathrm{m})\end{array}$ & $\begin{array}{c}\text { Maximum size at } \\
\text { interest region } \\
(\mu \mathrm{m})\end{array}$ \\
\hline Cel 30 & 14.52 & 12.02 & 2.80 \\
Cel 35 & 11.41 & 9.25 & 2.70 \\
Cel 40 & 4.71 & 3.88 & 2.50 \\
Cel $40 / 120$ & 5.14 & 7.10 & 2.10 \\
\hline
\end{tabular}

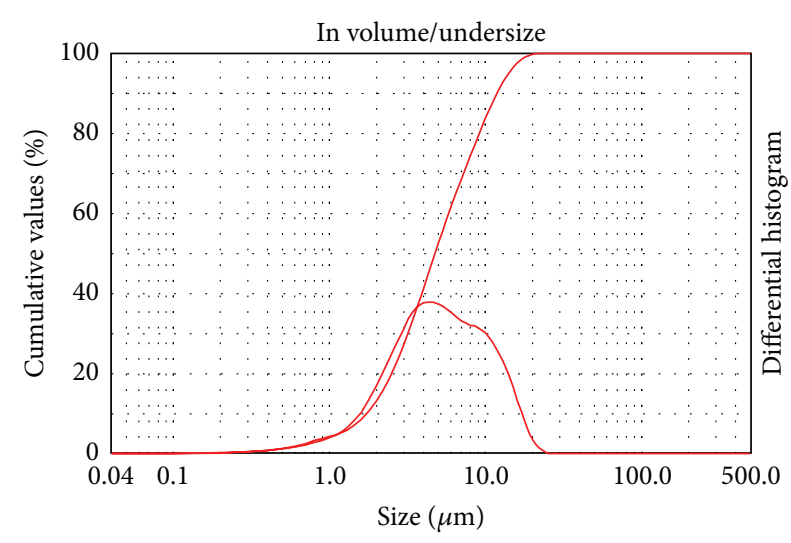

Figure 4: Typical result of the particle size analysis ( $\mathrm{Cel} \mathrm{40).}$

This explanation could be supported by the FT-IR results, which revealed that $\mathrm{Cel} 40$ was the intermediate product of the carbon structure. The average particle size of $\mathrm{Cel} 40 / 120$ sample, which was the $\mathrm{Cel} 40$ cellulose sample treated at $1,200^{\circ} \mathrm{C}$, was $5.14 \mu \mathrm{m}$. During the carbonization process at $1,200^{\circ} \mathrm{C}$, the carbon structure was formed with weight loss and the bonding force was simultaneously increased.

As previously mentioned, in this experiment the fine cellulose particles were obtained by the sedimentation method. Although the settling rate of the particles in the dope was different between the samples, the average particle size of the acquired cellulose particles, which are identified as the "maximum size at interest region" in Table 3, showed a similar size ranging from $2.8 \mu \mathrm{m}$ to $2.1 \mu \mathrm{m}$.

3.2.2. Morphologies of the Cellulose Particles. The study examining the dispersion of cellulose particles in the dope was conducted using chemical treatment and physical treatment methods. At first, the chemical method using $\mathrm{LiCl}$ as an additive could be expected to result in cellulose swelling and dissolving [16]. Figure 5 shows the morphologies of (a) the original cellulose particles and (b) the chemically treated cellulose particles. The shape of the cellulose is a linear chain made of $\mathrm{D}$-glucose, which is related to its structure depending on $\left(\mathrm{C}_{6} \mathrm{H}_{10} \mathrm{O}_{5}\right)_{n}$ where $n$ is the number ranging from 100 to 10,000 . Chemical treatments, which consisted of ultrasonic treatments followed by surface treatment using $\mathrm{LiCl}$, removed the binding substance between the microfibrils by dissolving the glycosidic bond. The acidic-hydrolysis reaction would affect the dissolution. There seemed to be some limitations in 


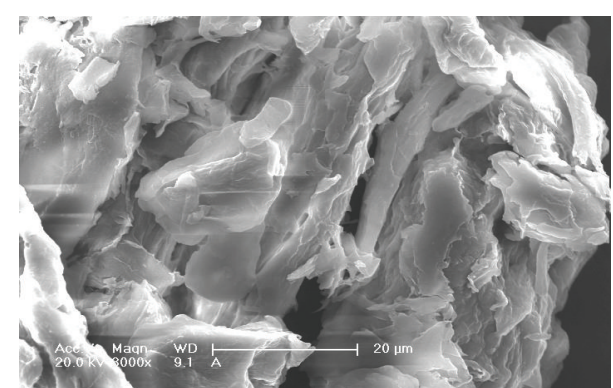

(a)

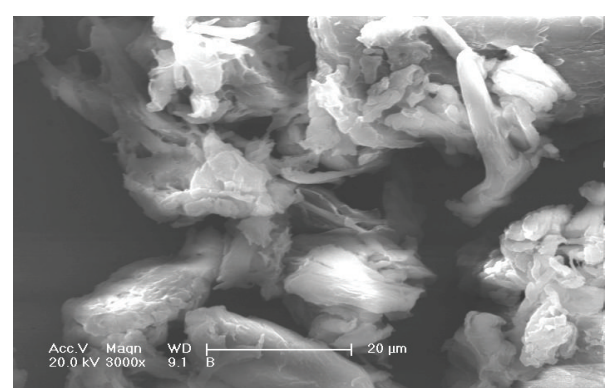

(b)

FIGURE 5: SEM micrographs $(\times 5,000)$ of the cellulose powders with chemical treatment. (a) Untreated cellulose powders. (b) Dispersed cellulose powders with $\mathrm{LiCl}$.

size reduction for the chemical method because of the linkage between the microfibril chains due to the hydrogen bonding that took place during the washing process with the water that was used to eliminate the $\mathrm{Li}^{+}$ions. This made it difficult to separate the particles from each other when the sample was dried in the air. Finally, the cellulose particles treated chemically were too large to spin through the nozzle when they were mixed in the spinning dope.

The second method used for the dispersion of cellulose particles was a milling process after heat treatment. The heat-treated and milled cellulose particles were added as an additive before preparing the spinning dope. Temperatures of $300^{\circ} \mathrm{C}, 350^{\circ} \mathrm{C}, 400^{\circ} \mathrm{C}$, and $1,200^{\circ} \mathrm{C}$ were selected as the heat treatment conditions for achieving the optimum condition of dispersion.

After heat treatment, morphological changes could be observed in the microstructure, as shown in Figure 6. From the SEM photographs it can be seen that the content of the microdebris was reduced and the overall size became smaller as the heat treatment temperature increased. The size reduction of the cellulose particles was caused by the breakdown of anhydrous glucose bonding due to pyrolysis over $240^{\circ} \mathrm{C}$ (until the temperature reached $400^{\circ} \mathrm{C}$ ).

It could be suspected that the moisture was physically absorbed and the fine fibrils at the surface were thermally decomposed in the course of the heat treatment for temperatures up to $300^{\circ} \mathrm{C}$. For $\mathrm{Cel} 40$ and $\mathrm{Cel} \mathrm{35,} \mathrm{most} \mathrm{of} \mathrm{the}$ particles under $10 \mu \mathrm{m}$ in diameter could be compared to the particle size of Cel 30, which showed a diameter of about $20 \mu \mathrm{m}$. In the range of $260^{\circ} \mathrm{C}-350^{\circ} \mathrm{C}$, which was described in Section 3.1, a decrease in the particle size was consistent with the results of thermal gravimetric analysis, which showed a weight reduction because the anhydrous glucose ring was destroyed.

Even though the particle sizes of the Cel 40 sample and the Cel 35 sample were similar, there were differences in the surface shape. The surface of the Cel 40 sample was uneven, whereas the surface of the Cel 35 sample was relatively smooth. This could be explained by the fact that the organic substance that was left in a small amount until the temperature reached $350^{\circ} \mathrm{C}$ was removed when the temperature was around $400^{\circ} \mathrm{C}$, due to thermal decomposition. For Cel 40/120, the particle size increased. The growth in the layered structure of the carbon residue, which had been formed in the previous step, was thought to be due to the aromatization when the temperature was over $400^{\circ} \mathrm{C}$.

3.2.3. Dispersion of Cellulose Particles. Figure 7 represents the flattened shape of the spun PAN fibers that contained carbonized cellulose observed by the optical microscope. The black spots, which are the carbonized cellulose particles, could be observed when the spun fiber flattened at a pressure of 20,000 psi on a mirror-like polished metal plate. This was closely related to the morphology and properties of the carbonized cellulose particle size shown in Figure 6 and Table 3, but cellulose microparticles under the micrometer level could not be observed due to the limitations of the optical microscope. The carbonized cellulose at a temperature over $400^{\circ} \mathrm{C}$ could be observed in black; however, the cellulose particles were represented by particles that were slightly dark brown when the heat treatment temperature was lower, as shown in Figures 7(a) and 7(b).

The dispersion with the heat treatment of $400^{\circ} \mathrm{C}$ and $400^{\circ} \mathrm{C} / 1,200^{\circ} \mathrm{C}$ indicated a small difference in the fiber; thus, it can be concluded that excellent dispersion was achieved at those conditions. Figures 7(a) and 7(b) show that the particles were agglomerated slightly. Therefore, the dispersion of the cellulose particles in the dope was better when the heat treatment temperature was higher. These results came from the decomposition of the organic substance in the cellulose at a high temperature, which leads to weak binding of the cellulose particles, enabling them to break easily.

3.3. Chemical Structure of Cellulose. The changes in the chemical structure of cellulose with the heat treatment were analyzed by FT-IR spectra, as shown in Figure 8 . All the samples revealed the $\mathrm{O}-\mathrm{H}$ stretching absorbing band in $3,400 \mathrm{~cm}^{-1}$. For the Cel 00 sample, the absorbing band related to the $\mathrm{C}-\mathrm{H}$ stretching of the cellulose could be observed at $2,900 \mathrm{~cm}^{-1}$. Many absorbing bands related to cellulose were found, such as a $\mathrm{C}=\mathrm{O}$ vibration band at $1,635 \mathrm{~cm}^{-1}$, a $\mathrm{CH}_{2}$ bending band at $1,426 \mathrm{~cm}^{-1}$ [17], and a stretch band of C-O-C asymmetry at $1,106 \mathrm{~cm}^{-1}[18]$. The result of the $\mathrm{C}-\mathrm{O}-\mathrm{C}$ stretching band at $898 \mathrm{~cm}^{-1}$ in this sample meant that there was a small amorphous form in the cellulose structure [17]. 


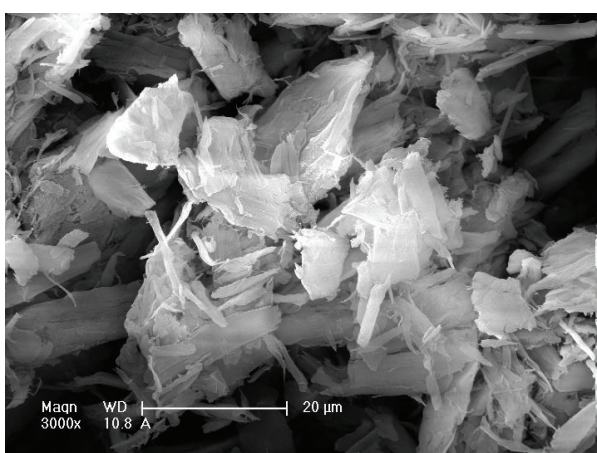

(a)

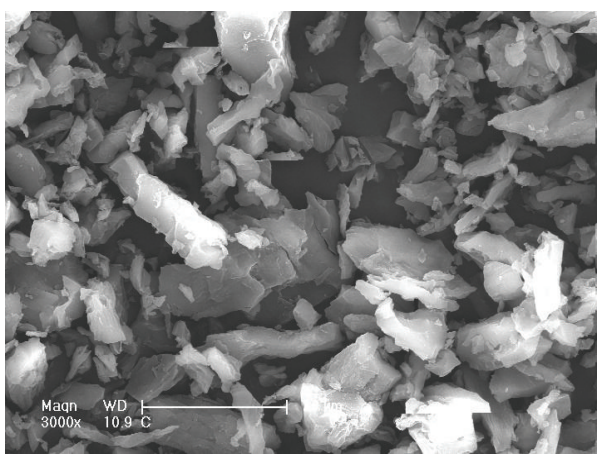

(c)

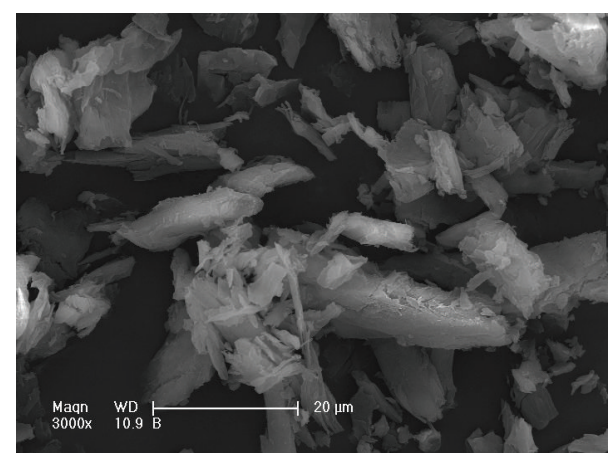

(b)

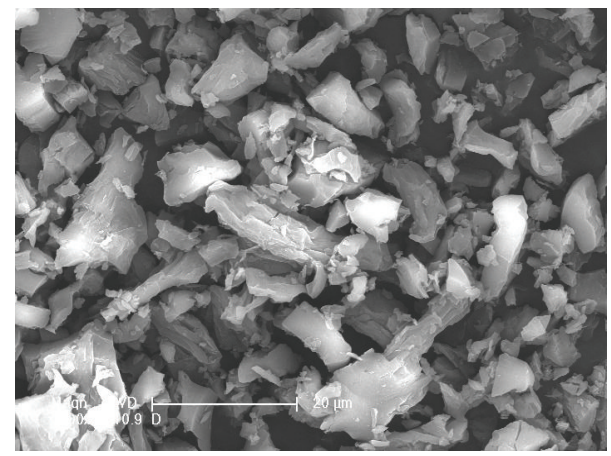

(d)

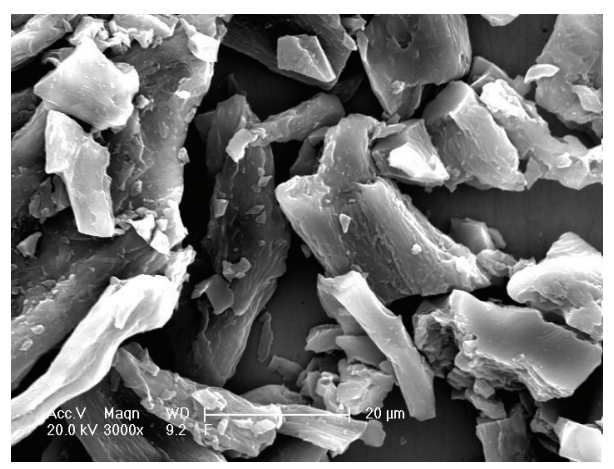

(e)

FIgURE 6: SEM micrographs $(\times 3,000)$ of the heat-treated cellulose particles. (a) Cel 00. (b) Cel 30. (c) Cel 35. (d) Cel 40. (e) Cel 40/120.

In the case of the Cel 35 sample, the characteristic cellulose peaks, such as $2,900 \mathrm{~cm}^{-1}$ and $890 \mathrm{~cm}^{-1}-1,500 \mathrm{~cm}^{-1}$, disappeared and the sample showed the absorbing of levoglucosan [19]. The final heat-treated sample of Cel 40 revealed the disappearance of the cellulose peaks and the levoglucosan peak, and the sample showed only a weak peak at $1,635 \mathrm{~cm}^{-1}$ related to $\mathrm{C}=\mathrm{O}$ vibration.

3.4. Crystal Structure of Cellulose. The crystal structure changes of the cellulose particles based on heat treatment condition are displayed in Figure 9. As shown, the results of the untreated cellulose particles agreed with crystal structure of JCPDS 03-0289 (natural cellulose). A maximum peak of (002) appeared at $2 \theta=22.8$, similar to other results reported by Wang et al. [20]. As the heat treatment temperature increased over $350^{\circ} \mathrm{C}$ ( $\mathrm{Cel} \mathrm{40)}$, the characteristic peaks of cellulose disappeared and then the structure showed an amorphous state. This result could be explained by the decomposition reaction of the side group, as shown in Figure 3. When the temperature increased up to $400^{\circ} \mathrm{C}$, broad peaks could be observed over $2 \theta=20-25$ and $2 \theta=40-45$ in $\mathrm{Cel} 40 / 120$, related to the graphite crystal structure. The result was coincident with the FT-IR results (Figure 8 ) and the TGA results (Figure 3).

\section{Conclusions}

The effects of cellulose particles on PAN dope have been studied. In order to achieve a stable and fine-dispersed state for PAN dope, chemical treatment and physical treatment were performed on the cellulose particles. The physical treatment included a milling process followed by a heat 


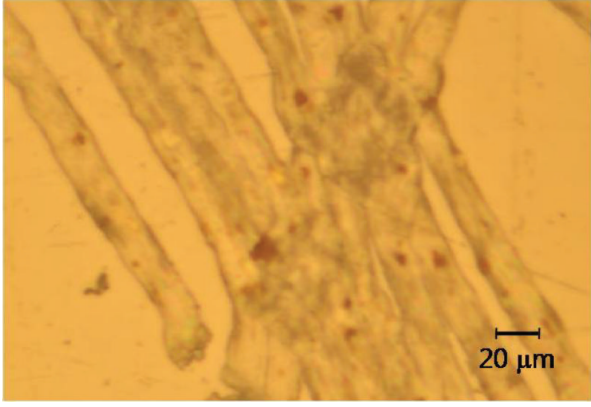

(a)

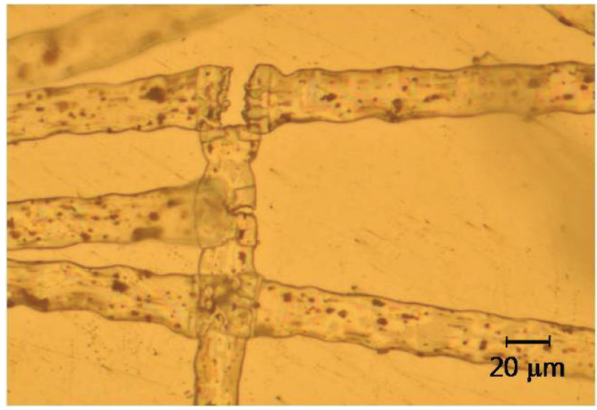

(c)

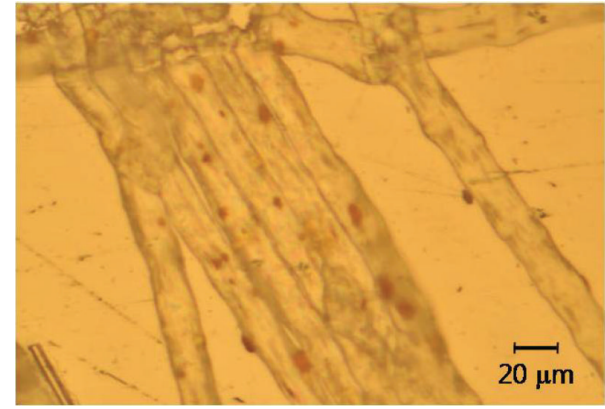

(b)

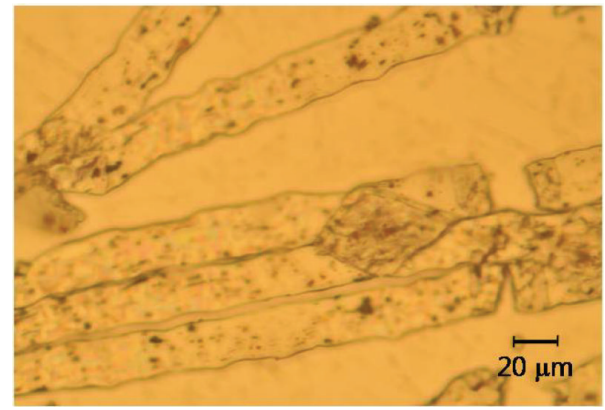

(d)

Figure 7: Optical micrographs $(\times 400)$ of the spun fiber with cellulose particles at various heat treatment conditions. (a) Cel 30 particles. (b) Cel 35 particles. (c) Cel 40 particles. (d) Cel 40/120 particles.

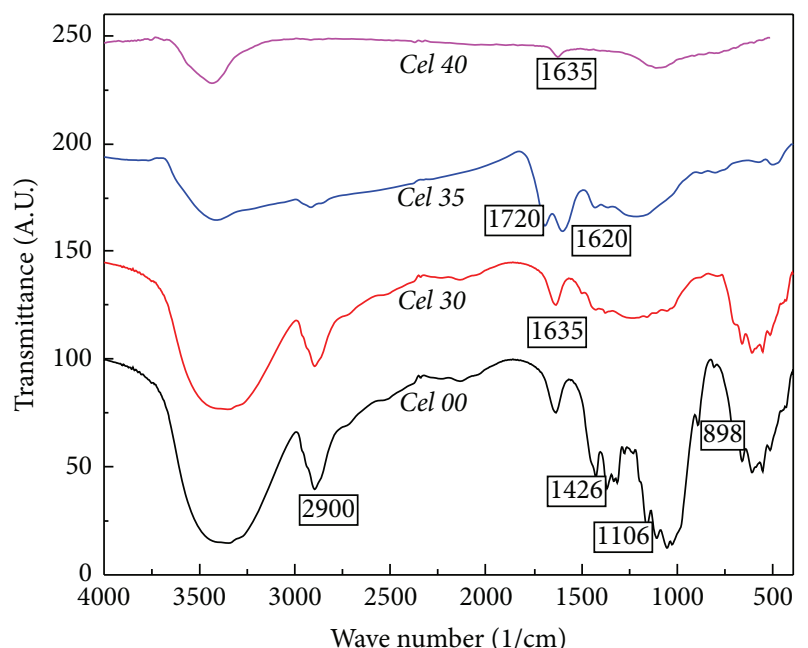

Figure 8: The FT-IR spectra of the heat-treated cellulose particles.

treatment process for carbonization of the cellulose. Finally, the following conclusions were obtained.

(1) Thermal/mechanical process has a better effect for preparing fine cellulose particles than the chemical treatment process in this study.

(2) The condition of heat treatment at $400^{\circ} \mathrm{C}$ in the air revealed the best properties for particle size (average $4.71 \mu \mathrm{m})$ and size distribution $(3.88 \mu \mathrm{m})$. The final

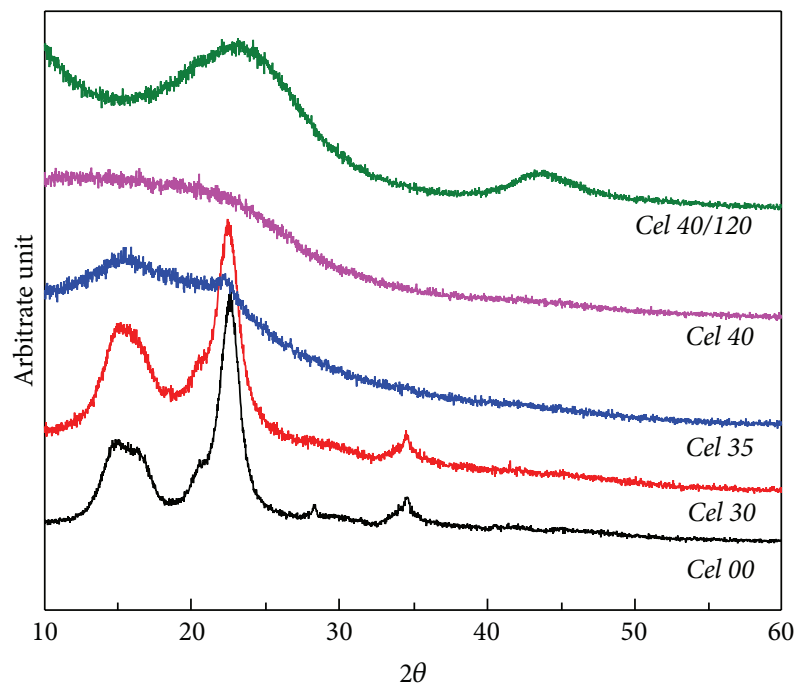

FIGURE 9: The XRD curves of the cellulose particles based on the heat treatment conditions.

particle size was selected in the range of $2.1 \mu \mathrm{m}-$ $2.8 \mu \mathrm{m}$ using the sedimentation method.

(3) Based on the results obtained from examining the dispersion characteristics of spun fiber with carbonized cellulose, the condition of carbonization at $400^{\circ} \mathrm{C}$ revealed relatively good dispersion of the cellulose particles in the dope. 


\section{Conflict of Interests}

The authors declare that there is no conflict of interests regarding the publication of this paper.

\section{Acknowledgments}

This research was financially supported by the "Fundamental R\&D Program for Technology of the Graduate Student Education Program for Research of Hybrid and Super Fiber Materials" through the Ministry of Trade, Industry \& Energy (MOTIE) and the Korea Institute for Advancement of Technology (KIAT) (N0000993).

\section{References}

[1] K. Morita, Y. Murata, A. Ishitani, K. Murayama, and A. Nakajima, "Characterization of commercially available PAN-based carbon fiber," Pure and Applied Chemistry, vol. 58, no. 3, pp. 455468,1986

[2] I. Mochida, S.-H. Yoon, N. Takano, F. Fortin, Y. Korai, and K. Yokogawa, "Microstructure of mesophase pitch-based carbon fiber and its control," Carbon, vol. 34, no. 8, pp. 941-956, 1996.

[3] H. M. Hawthorne, C. Baker, R. H. Bentall, and K. R. Linger, "High strength, high modulus graphite fibres from pitch," Nature, vol. 227, no. 5261, pp. 946-947, 1970.

[4] M. Endo, "Grow carbon fibers in the vapor phase," ChemTech, vol. 18, no. 9, pp. 568-576, 1988.

[5] A. G. Fazlitdinova, V. A. Tyumentsev, S. A. Podkopayev, and G. P. Shveikin, "Changes of polyacrylonitrile fiber fine structure during thermal stabilization," Journal of Materials Science, vol. 45, no. 15, pp. 3998-4005, 2010.

[6] Y. Xue, J. Liu, and J. Liang, "Kinetic study of the dehydrogenation reaction in polyacrylonitrile-based carbon fiber precursors during thermal stabilization," Journal of Applied Polymer Science, vol. 127, no. 1, pp. 237-245, 2013.

[7] J. Ding, X. Huang, G. Zhu, S. Chen, and G. Wang, "Mechanical performance evaluation of concrete beams strengthened with carbon fiber materials," Advances in Materials Science and Engineering, vol. 2013, Article ID 572151, 9 pages, 2013.

[8] J. Yang, J. J. Yoo, H. J. Jang, D. K. Yong, J. S. Won, and S. G. Lee, "Preparation and characterization of PAN-based carbon fibers having zirconia nanofibers," Textile Science and Engineering, vol. 49, no. 5, pp. 307-313, 2012.

[9] C. Pradere, J. C. Batsale, J. M. Goyhénèche, R. Pailler, and S. Dilhaire, "Thermal properties of carbon fibers at very high temperature," Carbon, vol. 47, no. 3, pp. 737-743, 2009.

[10] J.-W. Yang, H. N. Choi, Y. S. Chung, S. H. Kim, and S. G. Lee, "Preparation and properties of PAN-based carbon fibers having nano-cellulose," in Proceedings of the Asian Textile Conference, Daegu, Republic of Korea, 2011.

[11] A. Takaku and J. Shimizu, "Volume contraction and its significance in structural formation during the thermal stabilization of acrylic fibers," Journal of Applied Polymer Science, vol. 29, no. 4, pp. 1319-1326, 1984.

[12] J. D. Brooks and G. H. Taylor, Chemistry and Physics of Carbon, Marcel Dekker, New York, NY, USA, 1968.

[13] P. H. Brunner, "Beitragzur pyrolyse von cellulose fur Herstellung von Aktivkohlenaus Abfallstoffen," Ph.D. Dissertation no. 5705, Swiss Federal Institute of Technology, Zürich, Switzerland, 1976.
[14] D. Fengel and G. Wegener, Wood, De Gruyter, 1983.

[15] K. W. Kim, Analysis of natural fiber using pyrolysis [M.S. thesis], Chungnam National University, 2011.

[16] P. Navard and C. Cuissinat, "Cellulose swelling and dissolution as a tool to study the fiber structure," in Proceedings of the 7th International Symposium on Alternative Cellulose : Manufacturing, Forming, Properties, HAL ID: hal-00579326, Rudolstadt, Germany, 2006.

[17] D. Ciolacu, F. Ciolacu, and V. I. Popa, "Amorphous cellulosestructure and characterization," Cellulose Chemistry and Technology, vol. 45, no. 1-2, pp. 13-21, 2011.

[18] S. Ates, M. H. Akyildiz, and H. Ozdemir, "Effects of heat treatment on Calabrian pine (Pinus brutia Ten.) wood," BioResources, vol. 4, no. 3, pp. 1032-1043, 2009.

[19] K. Pielichowski and J. Njuguna, Thermal Degradation of Polymeric Materials, Rapra Technology Limited, 2005.

[20] B. Wang, M. Sain, and K. Oksman, "Study of structural morphology of hemp fiber from the micro to the nanoscale," Applied Composite Materials, vol. 14, no. 2, pp. 89-103, 2007. 

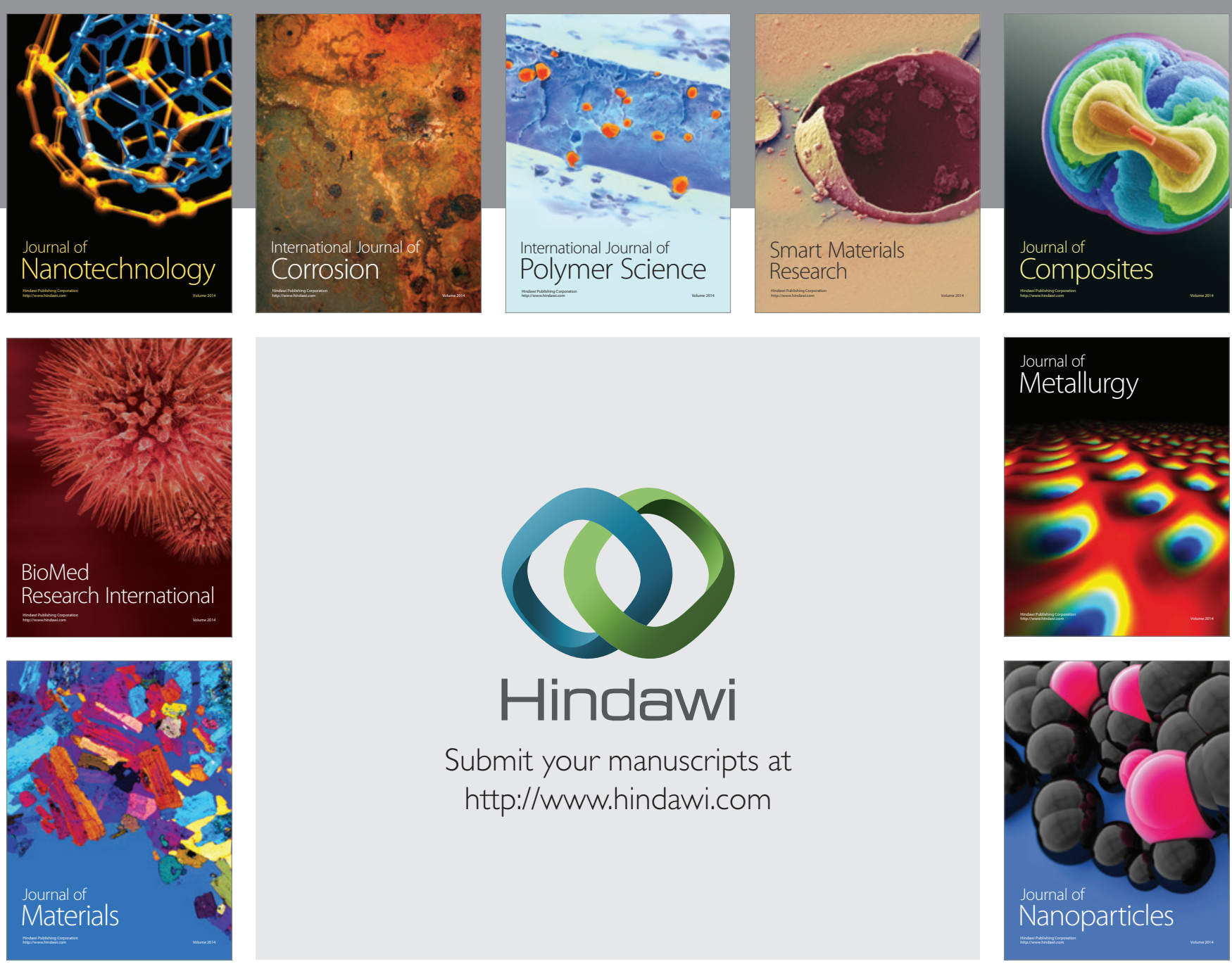

Submit your manuscripts at http://www.hindawi.com
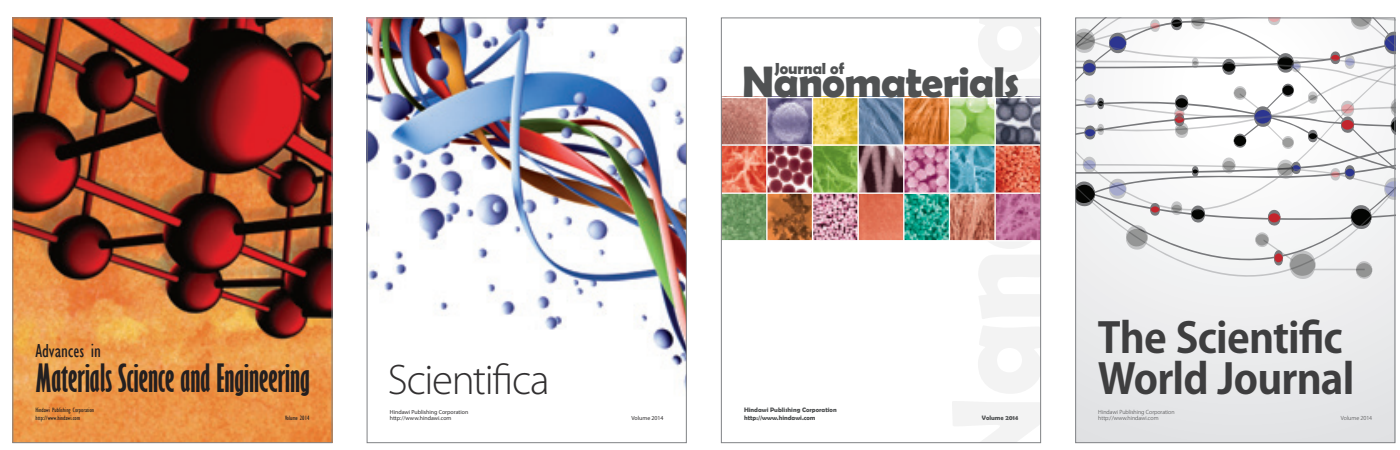

\section{The Scientific World Journal}
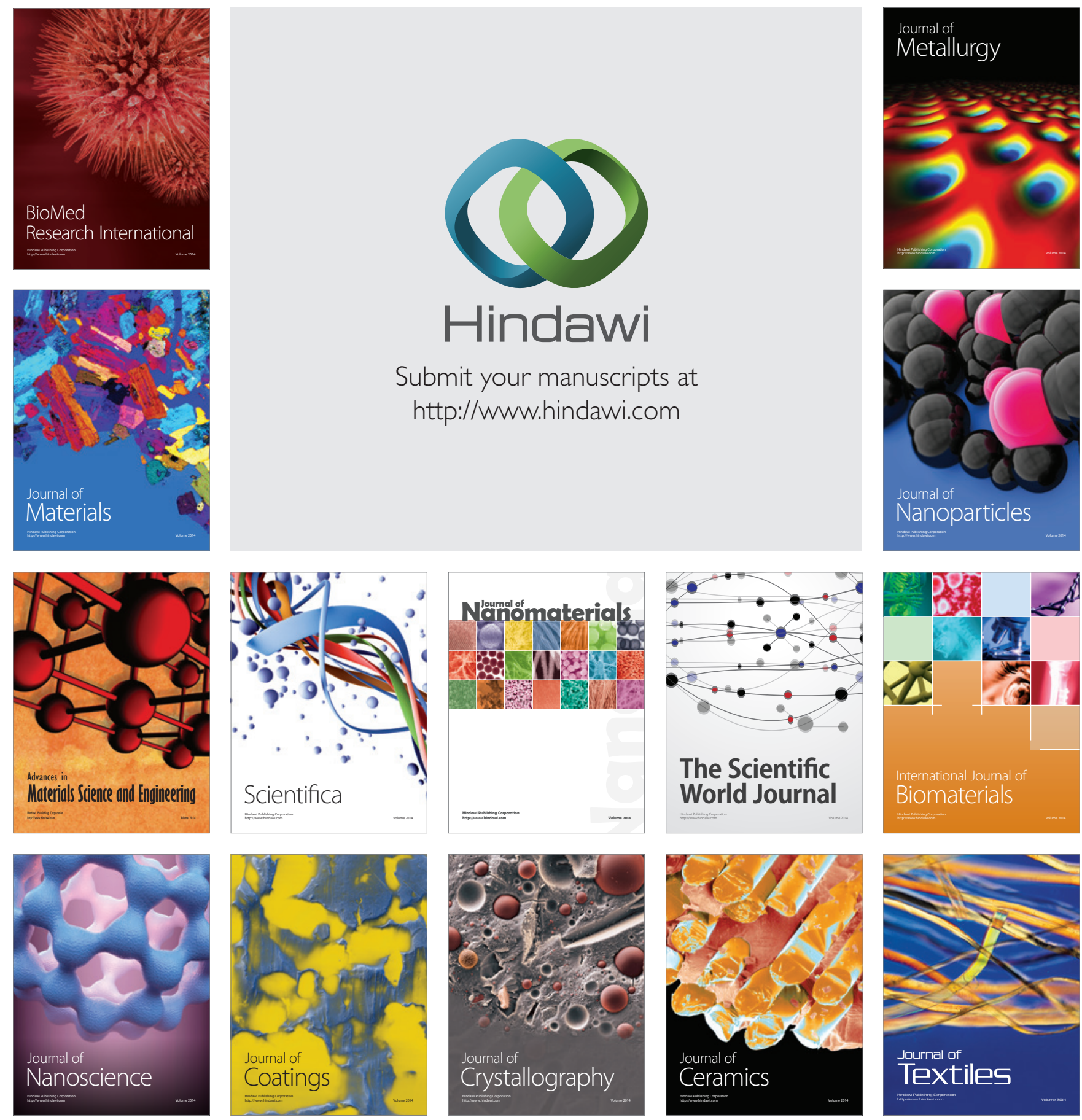